\title{
INFLUÊNCIA DA INCLINAÇÃO TRANSVERSAL E VELOCIDADE DE OPERAÇÃO SOBRE O DESEMPENHO DE DOSADORES PNEUMÁTICOS COM SEMENTE DE SOJA
}

\author{
Airton dos Santos Alonço ${ }^{1}$, Hendrigo Alberto Torchelsen da Silveira², Mateus Potrich Bellé3 , Dauto Pivetta \\ Carpes $^{4}$, Otávio Dias da Costa Machado 5
}

\begin{abstract}
RESUMO
O trabalho teve por objetivo avaliar a influência da inclinação transversal sobre o desempenho de três dosadores pneumáticos submetidos a diferentes velocidades de operação utilizando-se sementes de soja. $\mathrm{O}$ trabalho foi conduzido no Laboratório de Pesquisa e Desenvolvimento de Máquinas Agrícolas (LASERG), localizado na Universidade Federal de Santa Maria, com o auxilio de uma bancada que simula algumas condições operacionais de semeadura, como variação da rotação e inclinação de dosadores de sementes. Utilizou-se o delineamento experimental blocos casualizados com parcelas sub-subdivididas, com três fatores experimentais: inclinação transversal do dosador com três níveis $\left(+11^{\circ},-11^{\circ}\right.$ e nivelado), três dosadores de sementes pneumáticos e velocidade de deslocamento com três níveis $\left(5 ; 7,5\right.$ e $\left.10 \mathrm{~km} \mathrm{~h}^{-1}\right)$. Realizou-se a medição de 250 espaçamentos por repetição. Para a regularidade de distribuição avaliou-se a porcentagem de espaçamentos aceitáveis, duplos e falhos, e pelo coeficiente de variação dos dados coletados na esteira de sementes. Os resultados obtidos mostram que o aumento do espaçamento entre sementes foi influenciado pela variação da velocidade de deslocamento, impactando significativamente nos resultados médios de espaçamentos aceitáveis e falhos, além da precisão. Para o fator inclinação houve diferença significativa pelo teste de Tukey.
\end{abstract}

Palavras-chave: máquinas e implementos agrícolas, mecanização agrícola, semeadora-adubadora, Glycine max (L.)

\section{ABSTRACT \\ INFLUENCE OF CROSS SLOPE AND OPERATION SPEED ON THE PERFORMANCE OF PNEUMATIC SEED METERING WITH SOYBEAN SEEDS}

The study sought to evaluate the influence of cross slope on the performance of three pneumatic feeders submitted to different operation speeds using soybean seeds. The work was conducted at the Laboratory of Research and Development of Agricultural Machinery (LASERG), located at the Universidade Federal de Santa Maria, with the aid of a workbench that simulates certain operating conditions of sowing, such as variation of speed and slope of feeders. A randomized block design was used with split plots and three experimental factors: cross slope of three seed metering levels $\left( \pm 11^{\circ}\right.$ and leveled), three pneumatic seed feeders and three operation speeds $\left(5,7.5\right.$ and $\left.10 \mathrm{~km} \cdot \mathrm{h}^{-1}\right)$. Measuring consisted of evaluating 250 spacings per repetition. For the regularity of distribution the percentage of acceptable, double and flawed spacing was evaluated, and by the coefficient of variation of the data collected in the seed feeder. The results showed that increasing the seed spacing was influenced by variation of the operation speed, significantly impacting the average results of acceptable and flawed spacing, as well as precision. For the slope factor there was significant difference according to the Tukey test.

Keywords: agricultural machinery and implements, agricultural mechanization, planter, Glycine max (L.)

\section{Recebido para publicação em 10/01/2014. Aprovado em 19/03/2014.}

1 - Dr. Engenheiro Agrícola, Professor Associado, UFSM, Santa Maria - RS, Brasil, airtonalonco@gmail.com

2 - Engenheiro Agrícola, Mestre de Direito em Engenharia Agrícola, In Memoriam

3 - Engenheiro Agrônomo, Doutorando em Engenharia Agrícola - PPGEA, Universidade Federal de Santa Maria (UFSM), Santa Maria-RS, Brasil, mateuspotrichbelle@yahoo.com.br

4 - Engenheiro Agrônomo, Mestre em Engenharia Agrícola, Santa Maria - RS, Brasil, dautocarpes@gmail.com

5 - Engenheiro Agrônomo, Doutorando em Engenharia Agrícola - PPGEA/UFSM, Professor Adjunto Instituto Federal de Educação, Ciência e Tecnologia do Rio Grande do Sul, Bento Golçalves - RS, Brasil, otavio.machado@bento.ifrs.edu.br 


\section{INTRODUÇ̃̃O}

A semeadura é uma das mais importantes operações agrícolas associada à produtividade das culturas. Com isso, é de fundamental importância que esta operação seja realizada com o maior grau de qualidade e precisão possível. O equipamento responsável por esta operação, denominado semeadora, é definido por Machado et al. (2005) como sendo a máquina agrícola cuja função é colocar, no solo, os mais variados tipos de sementes, em densidade, espaçamento e profundidade recomendados para o pleno desenvolvimento produtivo da cultura.

Os principais componentes de uma semeadora são definidos por Delafosse (1986) em: dosadores de insumos, tubos condutores, reservatórios, chassi, órgãos complementares, sulcadores, recobridores, compactadores e mecanismos de acionamento. Atualmente, os dosadores de sementes são do tipo mecânicos e pneumáticos.

Dentre os fatores que podem interferir na precisão da semeadura, Reis e Forcellini (2002) citam a regularidade de distribuição de sementes e os erros de dosagem. A precisão da semeadura depende diretamente da precisão na dosagem executada pelos mecanismos dosadores de semente, que, segundo Dias (2009), é o órgão mais importante da semeadora.

As semeadoras de precisão em linha, para semeadura de grãos graúdos, utilizam em sua maioria dosadores mecânicos de disco horizontal e dosadores pneumáticos a vácuo. Reis et al. (2006) relatam tendência de utilização destes dosadores também para grãos miúdos (trigo e arroz), especialmente quando é empregada uma densidade de semeadura relativamente baixa para essas culturas. Além disso, Tourino et al. (2009) citam em seu trabalho que os dosadores pneumáticos podem proporcionar uma melhor distribuição das sementes e, consequentemente, uma maior produtividade.

Algumas variáveis têm influência sobre o desempenho dos mecanismos dosadores, sendo a inclinação de trabalho em relação ao solo uma característica comum a todos os tipos de dosadores, pois está submetida a todo o conjunto da semeadora, podendo ser simulada em laboratório através de bancada de ensaios (ABNT, 1994) e representada a campo pela declividade do terreno.

Uma bancada de ensaios de dosadores de sementes de arroz foi uma realidade empregada por Reis et al. (2007), possibilitando o controle da velocidade tangencial do disco dosador de sementes, além de proporcionar a mudança de inclinação dos dosadores em estudo.

A velocidade de semeadura é um fator determinante para quem precisa trabalhar no período recomendado como ideal para determinada cultura. Analisando a influência da velocidade da semeadura $\left(4 ; 6 ; 8 ; 10\right.$ e $\left.12 \mathrm{~km} \mathrm{~h}^{-1}\right)$ na distribuição longitudinal de sementes da soja, Jasper et al. (2011) observaram que o aumento da velocidade em dosadores pneumáticos implica em aumento nos espaçamentos múltiplos e redução dos espaçamentos aceitáveis. Cortez et al. (2006) concluíram que, ao se aumentar a velocidade na operação de semeadura no sistema pneumático, reduziu-se significativamente a quantidade de espaçamentos aceitáveis, aumentou-se a quantidade de espaçamentos falhos e não se alterou o estande. Reis et al. (2007), avaliando velocidades de semeadura em soja de 3,8 a 9,5 $\mathrm{km} \mathrm{h}^{-1}$, com disco alveolado horizontal, concluíram que a velocidade de $7,7 \mathrm{~km} \mathrm{~h}^{-1}$ apresentou maior percentual de falhas.

Silveira et al. (2005) avaliaram o espaçamento longitudinal de plantas de milho nas velocidades 3,$0 ; 4,5 ; 7,0 \mathrm{~km} \mathrm{~h}^{-1}$, com duas semeadoras: uma com dosador pneumático e outra com dosador mecânico do tipo disco. Esses autores encontraram os melhores valores de espaçamentos aceitáveis onde a cultura foi estabelecida pela semeadora com sistema de dosador pneumático na velocidade de $4,5 \mathrm{~km} \mathrm{~h}^{-1}$.

Pinheiro Neto et al. (2008) avaliaram o desempenho de duas semeadoras-adubadora em função de diferentes velocidades de deslocamento e condições de cobertura do solo, concluindo que aquela semeadora provida de dosador pneumático obteve melhores resultados, quanto aos espaçamentos aceitáveis.

De acordo com Kachman e Smith (1995), as medidas baseadas no espaçamento teórico como os índices de múltiplos, falhos, aceitáveis e a precisão podem sumarizar bem o desempenho de semeadoras quando analisados sob os aspectos de qualidade de dosificação e distribuição de sementes. Os autores consideraram um limite prático máximo para a precisão de $29 \%$, acima desse valor a precisão não é considerada adequada.

O presente trabalho teve por objetivo avaliar em laboratório o efeito de diferentes inclinações transversais sobre três dosadores pneumáticos de sementes em três velocidades de operação utilizando como parâmetro a distribuição longitudinal de sementes de soja. 


\section{MATERIAL E MÉTODOS}

O trabalho foi conduzido no Laboratório de Pesquisa e Desenvolvimento de Máquinas Agrícolas (LASERG) localizado na Universidade Federal de Santa Maria (UFSM) no ano de 2010. Os ensaios dos dosadores foram realizados em laboratório com o auxílio de uma bancada para ensaio de dosadores de semente (Figura 1), desenvolvida no LASERG, denominada de Bancada de Ensaios de Dosadores (BEDOSA). Esta estrutura possibilita o acoplamento de diversos tipos de dosadores e tem a função de acionar os mesmos. Para realização dos ensaios foram utilizadas sementes de soja com procedência comercial. As sementes não foram reutilizadas, e os reservatórios de sementes foram preenchidos no início de cada ensaio.

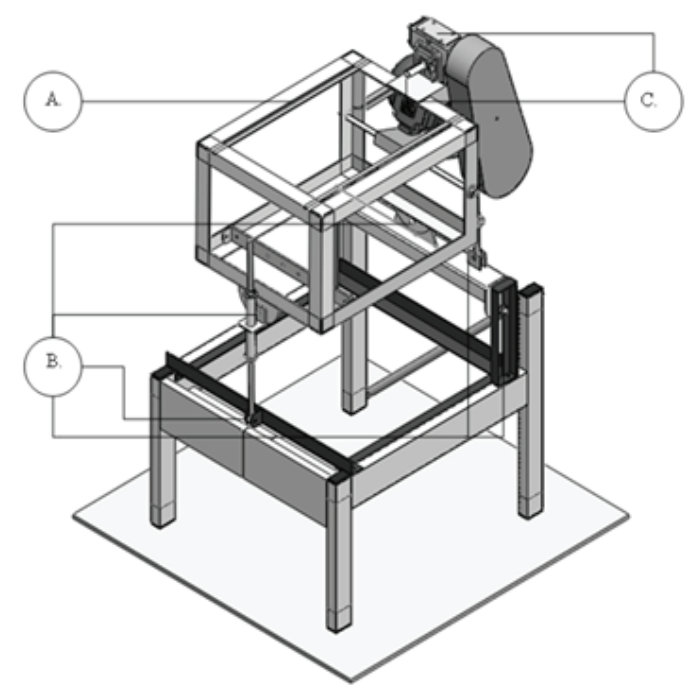

Figura 1. Leiaute da estrutura de sustentação bancada de ensaio de dosadores, onde A representa o local onde é acoplado o dosador de sementes, B são os dispositivos para regulagem da inclinação longitudinal e transversal e $\mathrm{C}$ é o redutor com o eixo de acoplamento do dosador.

A inclinação transversal de trabalho dos dosadores foi aplicada na bancada através de pontos compostos por rótulas e modificadas com o aumento e diminuição do curso de parafusos (Figura 1, item B). A ligação do movimento rotacional transmitido do motor, através do redutor (Figura 1, item C) até o eixo do dosador é realizada com o auxílio de um cardam, com juntas universais, o que possibilita a ligação de eixos não concêntricos, o que é importante, pois cada dosador possui uma característica dimensional própria.

Para contagem de espaçamentos entre sementes foi projetada uma esteira de borracha com 17,5 m de comprimento e $0,15 \mathrm{~m}$ de largura, que simula a velocidade de deslocamento de semeadora, esta esteira é revestida com feltro de forração agulhado vertical, com $3 \mathrm{~mm}$ de espessura, de fibra de poliéster, mesmo material utilizado para trabalho com dosadores de discos horizontais por Jasper et al. (2009).

Para gerar pressão negativa, necessária a captação das sementes pelo disco dosador, simulando o sistema pneumático, foi projetada uma estrutura de sustentação a uma turbina de geração de vácuo disponível no laboratório.

Os equipamentos necessários para a realização dos ensaios estão demonstrados na Figura 2, onde são destacadas a Bancada de Ensaio de Dosadores (BEDOSA), Bancada de Geração de Vácuo (BAR) e Esteira de medição dos espaçamentos, estando instalados no Laboratório prontos para uso.

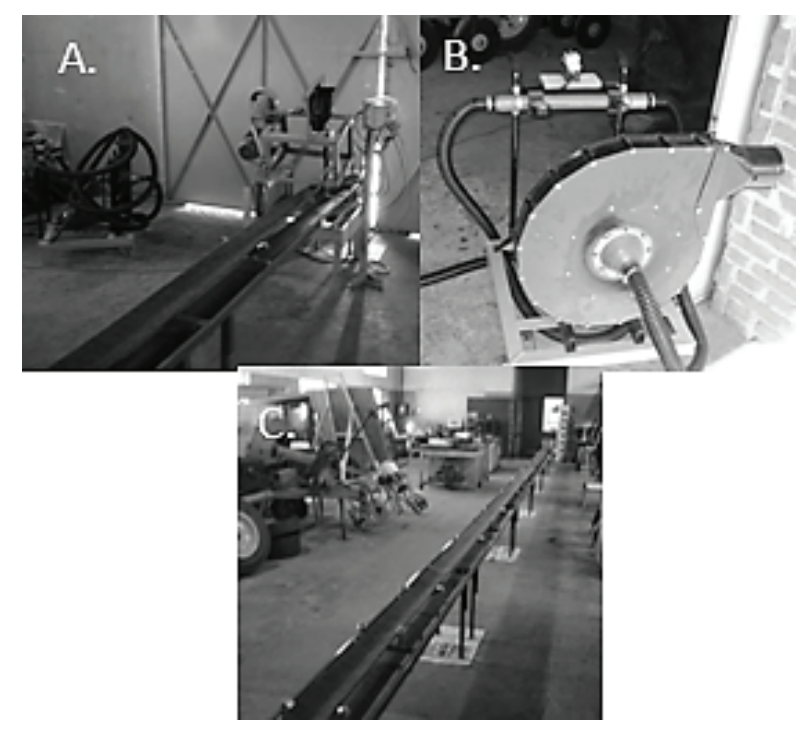

Figura 2. Imagens das bancadas, BEDOSA (A), BAR (B) e esteira de sementes (C)

Os dosadores de sementes utilizados no trabalho são comercialmente utilizados em semeadoras disponíveis no mercado, constituídos por um disco dosador vertical e com principio de coleta das sementes a vácuo (pressão negativa). Os dosadores foram designados por cores e as regulagens dos mecanismos dosadores foram aferidas de acordo com a recomendação dos fabricantes. $\mathrm{O}$ tubo condutor de sementes utilizado nos ensaios foi mantido o mesmo para cada dosador, com comprimento de $345 \mathrm{~mm}$ com abertura superior 
de $55 \times 37 \mathrm{~mm}$ e inferior com $35 \times 15 \mathrm{~mm}$, com inclinações de $8^{\circ}$ e $17^{\circ}$. A inclinação transversal do tubo seguia as mesmas inclinações dos dosadores.

Os dosadores pneumáticos a vácuo ensaiados no trabalho foram designados por cores, sendo que o dosador verde apresenta reservatório na lateral esquerda, o cinza e o amarelo na lateral direita (Figura 3).

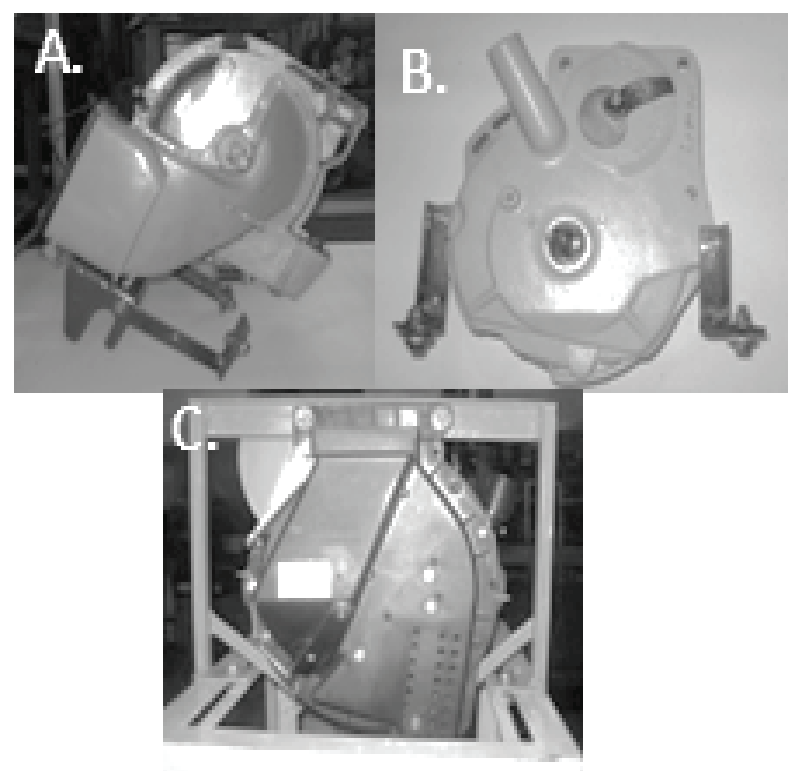

Figura 3. Dosadores de sementes pneumáticos verde (A), cinza (B) e amarelo (C)

As características dimensionais dos dosadores e seus discos apresentam-se no Quadro 1:

Quadro 1. Principais características dos dosadores avaliados nos ensaio

\begin{tabular}{lc}
\hline \multicolumn{2}{c}{ Dosador Verde } \\
\hline Pressão de trabalho $(\mathrm{kPa})$ & $-1,99$ \\
Diâmetro do disco (m)* & 0,200 \\
Número de orifícios do disco & 108 \\
Número de fileiras & 3 \\
Diâmetro do orifício (mm) & 4,37 \\
\hline \multicolumn{2}{c}{ Dosador Cinza } \\
\hline Pressão de trabalho (kPa) & $-3,5 \mathrm{a}-5,5$ \\
Diâmetro do disco (m)* & 0,215 \\
Número de orifícios do disco & 75 \\
Número de fileiras & 1 \\
Diâmetro do orifício (mm) & 4,5 \\
\hline \multicolumn{2}{c}{ Dosador Amarelo } \\
\hline Pressão de trabalho $(\mathrm{kPa})$ & $-5,0$ \\
Diâmetro do disco (m)* & 0,20 \\
Número de orifícios do disco & 84 \\
Número de fileiras & 1 \\
Diâmetro do orifício $(\mathrm{mm})$ & 4,5 \\
\hline
\end{tabular}

As velocidades e as inclinações transversais foram determinadas a partir da norma ISO 7256/1, com isso foram determinadas as velocidades de 5 $\mathrm{km} \mathrm{h}^{-1}$ mesma utilizada por Santos et al. (2008), 7,5 $\mathrm{km} \mathrm{h}^{-1}$, por ser uma intermediária e equidistante de $10 \mathrm{~km} \mathrm{~h}^{-1}$, máxima recomendada pelos fabricantes. As inclinações foram determinadas em $11^{\circ}$ para a esquerda e para direita, assim como nivelada.

A velocidade periférica dos discos dosadores excede os limites propostos pela FAO $\left(0,29 \mathrm{~m} \mathrm{~s}^{-1}\right)$ exceto na velocidade de $10 \mathrm{~km} \mathrm{~h}^{-1}$ para os dosadores amarelo e cinza. Já o dosador amarelo está dentro da recomendação da $\operatorname{ASAE}^{1}\left(0,315 \mathrm{~m} \mathrm{~s}^{-1}\right)$, ficando apenas a maior velocidade do dosador cinza $(0,350$ $\mathrm{m} \mathrm{s}^{-1}$ ) com valor acima desta recomendação. $\mathrm{O}$ conhecimento da velocidade periférica do disco dosador é muito importante por estar relacionada com a funcionalidade dos mecanismos raspadores e exclusores de sementes. A semente de soja utilizada foi da variedade Syngenta NK 7059 RR e peneira 6,5.

$\mathrm{O}$ delineamento experimental utilizado foi do tipo blocos casualizados com parcelas subsubdivididas, com três fatores experimentais: inclinação transversal do dosador com três níveis $\left( \pm 11^{\circ}\right.$ para esquerda, direita e nivelado), velocidade de deslocamento com três níveis $(5,7,5$ e $10 \mathrm{~km}$ $\mathrm{h}^{-1}$ ) e três dosadores de sementes pneumáticos, resultando em um fatorial $3 \times 3 \times 3$, com três repetições para cada tratamento, totalizando 81 unidades experimentais. As inclinações negativas e positivas foram consideradas a esquerda e direita, respectivamente, do sentido de deslocamento do conjunto trator-semeadora.

Em cada unidade experimental foi realizada a medição de 250 espaçamentos entre sementes. A regularidade de distribuição de sementes foi determinada conforme a ISO 7256/1 e ABNT (1994), sendo classificadas e determinadas as porcentagens de espaçamentos aceitáveis, duplos e falhos e pelo coeficiente de variação (ABNT, 1994 e Kachman; Smith, 1995) dos dados coletados na esteira de sementes. Espaçamentos aceitáveis são aqueles entre 0,5 e 1,5 vezes o espaçamento médio de referência $\left(\mathrm{X}_{\text {ref. }}\right)$, duplos os espaçamentos menores que 0,5 vezes o $X_{\text {ref. }}$ e falhos para espaçamentos maiores que 1,5 vezes o $X_{\text {ref. }}$. A densidade de semeadura por hectare utilizada foi de 311.111 sementes por hectare e 14 sementes por metro linear, correspondendo a recomendação da

2 - De acordo com Delafosse (1986)

\section{REVENG}


EMBRAPA (2010). O espaçamento entre linhas foi de $0,45 \mathrm{~m}$ e o espaçamento médio de referência $\left(\mathrm{X}_{\text {ref. }}\right)$ foi de $71,4 \mathrm{~mm}$.

Os dados foram analisados estatisticamente com o auxílio do Software Assistat, Versão 7.5 beta (SILVA; AZEVEDO, 2002). As porcentagens de espaçamentos aceitáveis, múltiplos e falhos coletados foram submetidas à análise de variância (ANOVA), as médias foram comparadas pelo teste de Tukey em nível de 0,05 de probabilidade de erro. Os dados foram submetidos ao teste de normalidade Kolmogorov-Smirnov e apresentaram-se normais.

\section{RESULTADOS E DISCUSSÃO}

As variáveis de resposta semente por metro linear (Sem $\left.\mathrm{m}^{-1}\right)$, precisão, espaçamentos múltiplos, aceitáveis e falhos estão descritas no Quadro 2.

Quadro 2. Análise de variância e do teste de médias para densidade de sementes, precisão e espaçamentos entre sementes de soja

\begin{tabular}{cccccc}
\hline Fatores & \multicolumn{5}{c}{ Variáveis } \\
\cline { 2 - 6 } & Sem m $\mathrm{m}^{-1}$ & Precisão (\%) & Múltiplos (\%) & Aceitáveis (\%) & Falhos (\%) \\
\hline Inclinação (F1) & & & & & \\
$-11^{\circ}$ & $12,47 \mathrm{~b}$ & $27,84 \mathrm{a}$ & $24,93 \mathrm{a}$ & $46,64 \mathrm{~b}$ & $28,43 \mathrm{a}$ \\
Nivelado & $13,12 \mathrm{a}$ & $26,11 \mathrm{~b}$ & $20,15 \mathrm{~b}$ & $56,19 \mathrm{a}$ & $23,66 \mathrm{~b}$ \\
$11^{\circ}$ & $12,52 \mathrm{~b}$ & $27,78 \mathrm{a}$ & $23,29 \mathrm{a}$ & $49,04 \mathrm{~b}$ & $27,67 \mathrm{a}$ \\
Dosador (F2) & & & & & \\
Amarelo & $12,02 \mathrm{~b}$ & $27,50 \mathrm{a}$ & $21,50 \mathrm{~b}$ & $48,24 \mathrm{~b}$ & $30,27 \mathrm{a}$ \\
Verde & $13,71 \mathrm{a}$ & $26,87 \mathrm{a}$ & $24,68 \mathrm{a}$ & $53,42 \mathrm{a}$ & $21,90 \mathrm{~b}$ \\
Cinza & $12,38 \mathrm{~b}$ & $27,37 \mathrm{a}$ & $22,19 \mathrm{~b}$ & $50,21 \mathrm{ab}$ & $27,60 \mathrm{a}$ \\
Velocidade (F3) & & & & & \\
5,0 & 12,87 & $26,91 \mathrm{a}$ & $20,18 \mathrm{~b}$ & $55,60 \mathrm{a}$ & $24,22 \mathrm{~b}$ \\
7,5 & 12,78 & $27,25 \mathrm{a}$ & $22,64 \mathrm{~b}$ & $50,52 \mathrm{~b}$ & $26,84 \mathrm{ab}$ \\
10,0 & 12,46 & $27,56 \mathrm{a}$ & $25,55 \mathrm{a}$ & $45,75 \mathrm{c}$ & $28,70 \mathrm{a}$ \\
Teste F & & & & & \\
Inclinação (F1) & $13,88 *$ & $14,32 *$ & $17,71 *$ & $28,51 * *$ & $22,81 * *$ \\
Dosador (F2) & $52,86 * *$ & $2,21 \mathrm{~ns}$ & $10,86 * *$ & $7,68 * *$ & $24,26 * *$ \\
Velocidade (F3) & $1,09 \mathrm{~ns}$ & $1,89 \mathrm{~ns}$ & $12,21 * *$ & $28,38 * *$ & $6,70 * *$ \\
F1 x F2 & $7,02 * *$ & $0,42 \mathrm{~ns}$ & $6,72 * *$ & $3,72 *$ & $2,39 \mathrm{~ns}$ \\
F1 x F3 & $0,66 \mathrm{~ns}$ & $0,77 \mathrm{~ns}$ & $0,31 \mathrm{~ns}$ & $0,58 \mathrm{~ns}$ & $0,65 \mathrm{~ns}$ \\
F2 x F3 & $0,84 \mathrm{~ns}$ & $1,10 \mathrm{~ns}$ & $1,61 \mathrm{~ns}$ & $0,36 \mathrm{~ns}$ & $0,50 \mathrm{~ns}$ \\
F1 x F2 x F3 & $1,31 \mathrm{~ns}$ & $0,47 \mathrm{~ns}$ & $1,16 \mathrm{~ns}$ & $0,30 \mathrm{~ns}$ & $0,93 \mathrm{~ns}$ \\
C. V. (\%) & & & & \\
Inclinação (F1) & 3,93 & 4,94 & 13,17 & 9,56 & 10,49 \\
Dosador (F2) & 5,01 & 4,27 & 11,59 & 9,69 & 16,97 \\
Velocidade (F3) & 8,44 & 4,53 & 17,56 & 9,49 & 16,61 \\
Média geral & 12,70 & 27,24 & 22,79 & 50,62 & 26,59 \\
\hline
\end{tabular}

Em cada coluna, para cada fator, médias seguidas de mesmas letras minúsculas não diferem entre si, pelo teste de Tukey, a 0,05 de probabilidade. $n s=$ não-significativo $(\mathrm{P} \geq 0,05) ; *$ significativo $(0,05>\mathrm{P} \geq 0,01) ; * *$ significativo $(\mathrm{P}<0,01)$, C.V. coeficiente de variação. 
Para os dados de precisão, descritos no Quadro 2, não houve variação dessa variável para os fatores dosador e velocidade, somente houve diferença significativa para o fator inclinação, sendo a posição nivelada a que obteve o melhor valor de precisão, de acordo com Kachman e Smith (1995).

Os resultados das porcentagens de espaçamentos múltiplos, para o fator velocidade de deslocamento da semeadora, mostraram o aumento deste índice com o aumento da velocidade, porém, não apresentando diferenças significativas entre as duas primeiras velocidades.

Os resultados médios de espaçamentos aceitáveis, descritos no Quadro 2, mostram que com o aumento da velocidade este índice diminui significativamente, resultados que concordam com Canova et al. (2007), que trabalhando com velocidades de 6,0;8,0 e 9,0 $\mathrm{km} \mathrm{h}^{-1}$, encontraram resultados de espaçamentos aceitáveis, inversamente proporcionais ao aumento da velocidade, extrapolando os limites toleráveis. Também, Cortez et al. (2006) encontraram diferenças significativas de espaçamentos aceitáveis com o aumento de velocidade $(4,24 ; 4,88$ e $6,00 \mathrm{~km} \mathrm{~h}^{-1}$ ), em uma semeadora pneumática, concordando com os resultados encontrados. Os resultados dos espaçamentos aceitáveis encontramse semelhantes aos observados por Tourino et al. (2007) para a densidade de 13 sementes por metro linear em uma semeadora pneumática.

A degradação do percentual de espaçamentos aceitáveis com o aumento da velocidade está vinculada a dificuldade dos raspadores em retirar as sementes duplas fixadas aos alvéolos do disco. Além disso, nesses casos pode haver a raspagem das sementes normais, ocasionando espaçamentos falhos na distribuição.

No Quadro 2, está descrito os resultados médios de espaçamentos falhos, sendo a posição nivelada a melhor, o dosador verde o que obteve menor índice de falhos e as velocidades 5,0 e $7,5 \mathrm{~km} \mathrm{~h}^{-1}$, as que obtiveram resultados semelhantes e menores que a velocidade $10,0 \mathrm{~km} \mathrm{~h}^{-1}$.

Como todas as variáveis de avaliação, descritas no Quadro 2, enfatizaram a melhor média de todas as variáveis analisadas para a posição nivelada, a velocidade de $5 \mathrm{~km} \mathrm{~h}^{-1}$ a que apresenta médias significativamente superiores para os espaçamentos aceitáveis, o dosador verde superior para as médias de densidade e espaçamentos falhos, porém inferior ao outros para os espaçamentos múltiplos. Com isso, o dosador verde obteve $2,1 \%$ de variação da densidade de sementes em relação à recomendada, ficando mais eficiente que o dosador cinza e o amarelo.

No Quadro 3 estão apresentadas as médias da densidade de semeadura na interação entre os fatores inclinação e dosador.

Quadro 3. Desdobramento de médias de densidade de semeadura $\left(\mathrm{sem} \mathrm{m}^{-1}\right)$ da interação inclinação $\mathrm{x}$ dosador

\begin{tabular}{cccc}
\hline \multirow{2}{*}{ Inclinação } & \multicolumn{3}{c}{ Dosador } \\
\cline { 2 - 4 } & Amarelo & Verde & Cinza \\
\hline$-11^{\circ}$ & $11,38 \mathrm{bC}^{*}$ & $13,73 \mathrm{aA}$ & $12,31 \mathrm{aB}$ \\
Nivelada & $13,16 \mathrm{aAB}$ & $13,62 \mathrm{aA}$ & $12,57 \mathrm{aB}$ \\
$11^{\circ}$ & $11,52 \mathrm{bB}$ & $13,79 \mathrm{aA}$ & $12,26 \mathrm{aB}$ \\
\hline
\end{tabular}

*Médias seguidas pela mesma letra maiúscula na linha e minúscula na coluna, não diferem entre si, ao nível de 0,05 de probabilidade, pelo teste de Tukey; DMS para colunas $=0,72 ;$ DMS para linhas $=0,80$

A análise de densidade de sementes diferiu estatisticamente somente para os fatores inclinação e dosador, ou seja, a densidade de semeadura não sofre influência da velocidade de deslocamento da semeadora, sendo a melhor média desta variável na posição nivelada e para o dosador verde. Mas, com o que pode ser observado, fica claro que somente o dosador amarelo sofre diferenças significativas com a mudança de inclinação, com isso, os outros dosadores não foram significativamente influenciados pela inclinação. Esses efeitos são incrementados, pois provavelmente os mecanismos raspadores de sementes do dosador amarelo, ao estarem em uma condição de inclinação, acabam raspando algumas sementes do disco, causando um espaçamento falho pela ausência de uma semente, reduzindo a densidade de semeadura desejada.

\section{REVENG}


Estão apresentados no Quadro 4 os espaçamentos múltiplos na interação entre os fatores inclinação e dosador.

Quadro 4. Desdobramento de médias de espaçamentos múltiplos (\%) da interação inclinação $\mathrm{x}$ dosador, com soja

\begin{tabular}{cccc}
\hline \multirow{2}{*}{ Inclinação } & \multicolumn{3}{c}{ Dosador } \\
\cline { 2 - 4 } & Amarelo & Verde & Cinza \\
\hline$-11^{\circ}$ & $23,82 * \mathrm{bA}$ & $24,67 \mathrm{bA}$ & $26,31 \mathrm{bA}$ \\
Nivelada & $19,78 \mathrm{aA}$ & $21,51 \mathrm{aA}$ & $19,15 \mathrm{aA}$ \\
$11^{\circ}$ & $20,89 \mathrm{bA}$ & $27,87 \mathrm{bB}$ & $21,11 \mathrm{aA}$ \\
\hline
\end{tabular}

Médias seguidas pela mesma letra maiúscula na linha $\mathrm{e}$ minúscula na coluna, não diferem entre si, ao nível de 0,05 de probabilidade, pelo teste de Tukey; DMS para colunas $=3,41$; DMS para linhas $=3,32$.

O dosador verde mostrou-se menos eficiente quanto ao índice de espaçamentos múltiplos do que os outros, na inclinação para esquerda $\left(-11^{\circ}\right)$. Entretanto, nas outras inclinações não houve diferenças significativas entre os dosadores. Este efeito está associado a maior exposição da semente junto ao disco dosador pela inclinação positiva, que favorece a entrada das mesmas na parte interna do dosador e dificulta a raspagem das duplas pelos mecanismos raspadores. Esse mesmo efeito é observado nos dosadores cinza e amarelo, onde, nesse caso, é a inclinação negativa que favorece a entrada de sementes dentro destes dosadores, proporcionando pior desempenho.

Os resultados de espaçamentos múltiplos se mostraram semelhantes aos encontrados por Tourino et al. (2007) que, estudando uma semeadora equipada com dosador pneumático, encontraram valores de 24,8 e $28,4 \%$ em dois anos de experimento.

No Quadro 5 estão desdobrados os resultados médios de espaçamentos aceitáveis, na qual pode ser visualizado que cada dosador se comporta de forma diferente, quando a inclinação se modifica, entretanto, como visto no Quadro 2, a posição nivelada apresenta os melhores resultados, independente do dosador utilizado.
Quadro 5. Desdobramento de médias de espaçamentos aceitáveis (\%) da interação inclinação $\mathrm{x}$ dosador, com soja

\begin{tabular}{cccc}
\hline \multirow{2}{*}{ Inclinação } & \multicolumn{3}{c}{ Dosador } \\
\cline { 2 - 4 } & Amarelo & Verde & Cinza \\
\hline -11 & $42,35^{*} \mathrm{bB}$ & $53,15 \mathrm{abA}$ & $44,40 \mathrm{bB}$ \\
Nivelada & $55,87 \mathrm{aA}$ & $57,69 \mathrm{aA}$ & $55,02 \mathrm{aA}$ \\
$11^{\circ}$ & $46,49 \mathrm{bA}$ & $49,42 \mathrm{bA}$ & $51,20 \mathrm{aA}$ \\
\hline
\end{tabular}

*Médias seguidas pela mesma letra maiúscula na linha e minúscula na coluna, não diferem entre si, ao nível de 0,05 de probabilidade, pelo teste de Tukey; DMS para colunas $=5,94 ;$ DMS para linhas $=6,16$

O dosador amarelo apresentou sensível redução dos aceitáveis nas condições de inclinação positiva e negativa. Entretanto, em relação à condição nivelada para este dosador, o pior resultado foi observado quando a inclinação esteve positiva, onde esta proporcionou que as sementes no reservatório na posição direito do sentido de deslocamento do conjunto tivessem maior facilidade de contato com o disco dosador, favorecendo a fixação das sementes nos orifícios e prejudicando o funcionamento do mecanismo raspador. Essa mesma explicação se aplica ao dosador cinza, que possui o reservatório do mesmo lado que o amarelo, do lado direito do sentido deslocamento do conjunto, sofrendo as mesmas influências desta condição.

O dosador verde, ao contrário do amarelo e cinza, apresenta o reservatório na posição esquerda e por isso a influência desta condição se aplicou quando o conjunto esteve na inclinação positiva.

\section{CONCLUSÕES}

- A inclinação transversal de trabalho interferiu negativamente no desempenho dos mecanismos dosadores estudados, sendo que os piores resultados foram encontrados quando a inclinação do reservatório dos dosadores favoreceu a entrada das sementes dentro do mesmo.

- O dosador verde apresentou os melhores resultados de espaçamentos aceitáveis e falhos, precisão e densidade de sementes. 
- Com o aumento da velocidade de deslocamento, ocorreu uma diminuição do percentual de espaçamentos aceitáveis.

\section{REFERÊNCIAS BIBLIOGRÁFICAS}

ABNT - Associação Brasileira de Normas Técnicas. Projeto de norma 04: 015.06 - 004: Semeadora de precisão - ensaio de laboratório - método de ensaio. São Paulo: 1994. 26p.

CANOVA, R.; SILVA, R.P.; FURLANI C.E.A.; CORTEZ, J.W. Distribuição de sementes por uma semeadora-adubadora em função de alterações mecanismo dosador e de diferentes velocidades de deslocamento. Engenharia na Agricultura, v.15, p.299-306, 2007.

CORTEZ, J.W.; FURLANI, C.E.A.; SILVA, R.P.; LOPES, A. Distribuição longitudinal de sementes de soja e características físicas do solo no plantio direto.

Engenharia Agrícola, v.26, p.502-510, 2006.

DELAFOSSE, R.M. Máquinas sembradoras de grano gruesso. Santiago: Oficina Regional de La FAO para America Latina y el Caribe, 1986. 48p.

DIAS, V.O.; Desempenho de dois protótipos de semeadoras-adubadoras para plantio direto. 2009. 80f. Disserrtação (Mestrado em Engenharia Agrícola). UFSM, Santa Maria, 2009.

DIAS, V.O.; ALONÇO, A.S.; BAUMHARDT, U.B.; BONOTTO G.J. Distribuição de sementes de milho e soja em função da velocidade e densidade de semeadura. Ciência Rural, v.39, p.1721-1728, 2009.

EMBRAPA - Empresa Brasileira de Pesquisa Agropecuária. Sistema de produção-soja. < http:// sistemasdeproducao.cnptia.embrapa.br $>$. 18 Jun. 2010 .

ISO - International Organization for Standardization: 7256/1: Sowing equipment methods of test: Part 1. Single seed drills (precision drills). Geneva: ISO 1982. 16p.

JASPER, M.; ASSUMPÇÃO, P.S.M; ROCIL,
J.; GARCIA L.C., Velocidade de semeadura da soja. Revista Engenharia Agrícola, v.31, p.102110, 2011.

KACHMAN, S.D.; SMITH, J.A. Alternative measures of accuracy in plant spacing for planters using single seed metering. Transactions of the ASAE, v.38, p.379-387,1995.

PINHEIRO NETO, R..; BRACCINI, A.L.; SCAPIM, C.A.; BORTOLOTTO, V.C.; PINHEIRO, A.C. Desempenho de mecanismos dosadores de sementes em diferentes velocidades e condições de cobertura do solo. Acta Scientiarum Agronnomy. v.30, p.611-617, 2008.

MACHADO, A.L.T.; REIS, A.V.; MORAES, M.B.; ALONÇO, A.S. Máquinas para semeadura e adubação. In: Máquinas para preparo do solo, semeadura, adubação e tratamentos culturais. 2.ed. Pelotas: UFPEL, 2005. p.101-190.

REIS, A.V.; FORCELLINI, F.A. Análise da precisão funcional da semeadora. Tecno Lógica, v.6, p.91-104, 2002.

REIS, A.V.; FORCELLINI, F.A.; RAMOS, U.A.P. Avaliação do diâmetro do orifício e da pressão de ar na dosagem pneumática de sementes de arroz. Revista Brasileira de Agrociência, v.12, p.191197, 2006.

REIS, A.V.; MACHADO, A.L.T.; BISOGNIN, A. Avaliação do desempenho de três mecanismos dosadores de sementes de arroz com vistas à semeadura de precisão. Revista Brasileira de Agrociência, v.13, p.393-398, 2007.

REIS, E.F.; MOURA, J.R.; DELMOND, J.G.; CUNHA, J.P.A.R. Características operacionais de uma semeadora-adubadora de plantio direto na cultura da soja (Glycine max (L.) Merril). Revista Ciências Técnicas Agropecuárias, Habana, v.16, p. 70-75, 2007.

SANTOS, A.P.; TOURINO, M.C.C.; VOLPATO, C.E.S. Qualidade de semeadura na implantação da cultura do milho por três semeadoras-adubadoras 
de plantio direto. Ciência e Agrotecnologia, v.32, p.1601-1608, 2008.

SILVA, F.A.S.E; AZEVEDO, C.A.V. Versão do programa computacional Assistat para o sistema operacional windows. Revista Brasileira de Produtos Agroindustriais, v.4, p.71-78, 2002.

SILVEIRA, J.C.M.; GABRIEL FILHO, A.; TIEPPO, R.C.; TORRES, D.G.B.; BALDESSIN JÚNIOR, A.; BOLIGON, F. Uniformidade de distribuição de plantas e estande de milho (Zea mays L.) em função do mecanismo dosador de sementes. Acta Scientiarum Agronomy, v.27, p.467-472, 2005.

TOURINO, M.C.C.; REZENDE, P.M.;ALMEIDA, L.G.P.; SILVA, L.A. Comparativo na uniformidade /distribuição de sementes em função do tipo de semeadoras. Revista Brasileira de Agrociência, v.13, p.383-392, 2007.

TOURINO, M.C.C.; REZENDE, P.M.; SILVA, L.A.; ALMEIDA, L.G.P. Semeadoras-adubadoras em semeadura convencional de soja. Ciência Rural, v.39, p.241-245, 2009. 